\title{
Technological coherence and the adaptive resilience of regional economies
}

\section{Silvia Rocchetta \& Andrea Mina}

To cite this article: Silvia Rocchetta \& Andrea Mina (2019) Technological coherence and the adaptive resilience of regional economies, Regional Studies, 53:10, 1421-1434, DOI: 10.1080/00343404.2019.1577552

To link to this article: https://doi.org/10.1080/00343404.2019.1577552

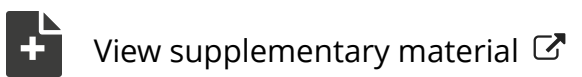

\footnotetext{
曲 Published online: 15 Mar 2019.
}

Submit your article to this journal $\pi$

LII Article views: 573

Q View related articles $\sqsubset$

View Crossmark data $\asymp$

Citing articles: 6 View citing articles 


\title{
Technological coherence and the adaptive resilience of regional economies
}

\author{
Silvia Rocchetta ${ }^{a}$ and Andrea Mina ${ }^{b}$
}

\begin{abstract}
This paper explores the effect of different regional technological profiles on the resilience of regional economies to exogenous shocks. It presents an empirical examination of the determinants of resilience through panel analyses of UK NUTS-III-level data for the period 2004-12. The results indicate that regions endowed with technologically coherent and not simply diversified - knowledge bases are better prepared to face an unforeseen downturn and display adaptive resilience. Moreover, local economies tend to be more adaptable if they innovate in sectors with the strongest growth opportunities, even though firms' entry does not appear to contribute significantly towards resilience.
\end{abstract}

\section{KEYWORDS}

resilience; adaptation; innovation; technological variety; financial crisis

JEL O30, O33, R11

HISTORY Received 2 October 2017; in revised form 17 January 2019

\section{INTRODUCTION}

In the context of recovery from the Great Recession the concept of adaptive resilience has gained traction in the literature. Adaptive resilience involves the capacity of a regional economy to absorb the effects of recessionary forces and the ability of its industrial and technological structure to react to exogenous shocks through adaptation and innovation (Martin, 2012). The evolution of regional economies is uneven (Porter, 2003; Gardiner, Martin, Sunley, \& Tyler, 2013; Saxenian, 1994) and interregional differences can become even sharper when tested by downturns (Dijkstra, Garcilazo, \& McCann, 2015; Organisation for Economic Co-operation and Development (OECD), 2014). Some regions appear to be more adaptable and able to absorb shocks while others experience decline. What can explain the differential performance of regions after and during a crisis? Martin (2012) argues that adaptive resilience may depend on factors such as: the formation of new firms, innovation, willingness to change, the diversity of regional economic structures and the availability of skilled labour. Related studies (e.g., Boschma, 2015; Essletzbichler, 2015) point out that diversification is an especially important driver of resilience because variety can alleviate the risks of sector-specific shocks and mitigate the short-run impact of a crisis on employment. Variety in complementary industries or technologies can arguably trigger useful knowledge spillovers (Boschma, 2015; Grabher \& Stark, 1997; Pike, Dawley, \& Tomaney, 2010). However, the development and exploitation of positive externalities may be more efficient when growth opportunities are consistent with the existing knowledge base and when processes of knowledge recombination involve technologically related inputs (Antonelli, Krafft, \& Quatraro, 2010; Fleming, 2001; Frenken, Van Oort, \& Verburg, 2007; Quatraro, 2010).

In this paper we theorize and test what kind of technological diversification drives adaptive resilience. To the best of our knowledge existing studies on resilience focus either on a single sector (e.g., Holm \& Østergaard, 2015) or on the composition of the local industrial structure (Delgado \& Porter, 2018; Sedita, De Noni, \& Pilotti, 2014). In the literature, however, technological knowledge has been broadly identified as a key driver of regional growth (see Kogler, Essletzbichler, \& Rigby, 2017, for a comprehensive discussion of this theme), but research on the effects of regional technological profiles on resilience is still scant. We address this gap by means of econometric analyses of a panel of 134 English NUTS-III regions covering the period 2004-12. We use employment and industry data

\footnotetext{
CONTACT

a silvia.rocchetta@ucd.ie

Spatial Dynamics Lab, School of Architecture, Planning \& Environmental Policy, University College Dublin, Dublin, Ireland

b (Corresponding author) andrea.mina@santannapisa.it

Scuola Superiore Sant'Anna \& EMbeDS, Pisa, Italy; and Centre for Business Research, Judge Business School, University of Cambridge, Cambridge, UK.

(6) Supplemental data for this article can be accessed at https://doi.org/10.1080/00343404.2019.1577552.
} 
from the UK Office for National Statistics (ONS) integrated with information from the European Patent Office's (EPO) PATSTAT database, grouping patents into eight technological classes and 121 subclasses according to the International Patent Classification (IPC). As we want to analyze the impact of different types of technological diversification on resilience, we use information on inventor location and three-digit technology codes to calculate different measures of diversification. The econometric evidence uncovers the crucial role of technological coherence. It also suggests that regions that innovate in high-tech sectors tend to be more resilient while the effect of new firms' entry is overall negligible.

The paper is structured as follows. The next section reviews the literature on adaptive resilience and profiles the theoretical line of the paper by specifying four research hypotheses. The third section presents the data, the construction of diversification indices and the variables included in the modelling exercise. The fourth section presents the estimation strategy and results. The fifth section sums up and discusses the main findings, the limitations of the study and then concludes with reference to its implications for future research and policy.

\section{LITERATURE REVIEW}

\section{What is resilience?}

The concept of resilience has been used in different contexts and with different connotations (Bristow \& Healy, 2014; Christopherson, Michie, \& Tyler, 2010; Reggiani, de Graff, \& Nijkamp, 2002). This has generated some conceptual ambiguity that has often made its operationalization for empirical testing difficult (Sensier, Bristow, \& Healy, 2016). 'Resilience' has been viewed from at least three different perspectives: engineering, ecological and adaptive. Earlier studies on 'engineering resilience' focused on the stability of a system working closely to equilibrium or a steady state, while 'ecological resilience' denotes the capacity of a system 'to absorb disturbance and reorganize while undergoing change so as to still retain essentially the same function, structure, identity and feedbacks' (Walker et al., 2006, p. 2).

A more recent interpretation of the concept as 'adaptive resilience' has been proposed in relation to a region's ability to reorganize economic structures to absorb the effect of a destabilizing shock (Martin, 2012). Resilience involves the regional economies' capacity to recover from an unexpected downturn as well as the capacity to reconfigure productive activities and develop new growth paths (Boschma, 2015). According to this literature resilience does not simply entail the return to a stable equilibrium state (Simmie \& Martin, 2010) but involves adaptation to exogenous change through innovation (Crescenzi, Luca, \& Milio, 2016; Saviotti, 1996). ${ }^{1}$ In evolutionary terms (Boschma \& Frenken, 2006; Boschma \& Martin, 2007) adaptation involves a path-dependent process shaped by the regions' endogenous pre-shock characteristics and by the regional system's ability to recombine knowledge so as to maintain satisficing growth paths in output and employment over time.
Adaptability, therefore, is not a static characteristic of the region but rather a dynamic characteristic that depends on continuous processes of localized Schumpeterian change in which 'pre-existing resources and capabilities often shape new growth paths, as these are rejuvenated and redeployed in new combinations' (Boschma, 2015, p. 736). This is consistent with a recombinant approach to growth whereby economic development consists in using known resources in a different way to realize new things with them (Weitzman, 1998).

Despite growing scholarly interest, comprehensive empirical evidence on the determinants of adaptive resilience is still scant. Martin (2012) provides useful guidance by developing the idea that adaptive resilience depends on a mix of factors such as entrepreneurship, the firms' willingness and ability to react to or trigger change, and the technological and skills endowment of the region. While these cannot be taken as a 'recipe' to make a region resilient, they constitute a set of interesting propositions that need to be further articulated and put to empirical test. Consistently with this approach, in his exploratory analysis of UK NUTS-I regions, Fingleton, Garretsen, and Martin (2012) argue that in order to explain resilience one should look at a region's prior economic performance, the structure of the economy and the region's innovation system (including the skills base and entrepreneurial culture). By analyzing the evolution of the steel technology cluster in Pittsburgh, Treado (2009) highlights that the reasons behind the cluster's ability to be resilient need to be found in local workers' expertise. Moreover, through the comparative case study of Ottawa and Waterloo in Canada, Wolfe (2010) argues that resilience is influenced by the characteristics of regional industrial structures and of civic capital, while Simmie and Martin (2010) stress the importance of local institutions, the creation of new knowledge and entrepreneurship in discussing the evolution of the cities of Cambridge and Swansea in the UK. ${ }^{2}$

\section{The sources of regional adaptive resilience}

Among the sources of resilience, variety of economic activities has figured prominently in the literature. Variety should prompt adaptive resilience and shape a region's capacity to absorb the negative effects of a downturn (Boschma, 2015; Fingleton \& Palombi, 2013). Jacobs (1969) already proposed that the exchange of cross-sectoral knowledge promotes externalities that foster innovation and trigger localized growth, a point also made by Pasinetti (1993) when he noted that an economy must increase variety over time in order to generate productive gains and limit structural unemployment due to a combination of product innovation and technical progress in production. A high degree of variety should favour the generation of spillovers and open up opportunities for the pursuit of new activities (Feldman \& Audretsch, 1999; Glaeser, Kallal, Scheinkman, \& Shleifer, 1992). Attaran (1986) and Frenken et al. (2007) argue that broader portfolio diversification can protect local labour markets from destabilizing factors (e.g., workers that have been made redundant could be absorbed by industries that are relatively less 
affected by a downturn). Grabher and Stark (1997) also emphasize the importance of diversity in enhancing regional economies 'adaptive capacity' and Boschma (2015) elaborates further that local economies with a higher degree of variety should be able to minimize the risks linked to idiosyncratic shocks and therefore favour adaptation. Following the Schumpeterian principle that technological capabilities are essential building blocks of growth processes, we formulate the following hypothesis:

\section{Hypothesis 1: The degree of regional technological variety has a positive effect on resilience.}

Simmie and Martin (2010) suggest that regional resilience is co-determined by endogenous sources of new knowledge and by particular decisions about the use of this knowledge. The degree of technological coherence of a region's technology portfolio can favour knowledge spillovers because it lowers the barriers for novelty generation and exploitation (Frenken et al., 2007). Holm and Østergaard (2015) have recently shown that related technological variety positively influenced the adaptive resilience of the information and communication technology (ICT) sector in Denmark after the burst of the dot.com bubble. Delgado and Porter (2018) make a similar point and argue that co-specialized and co-located resources can make regional industrial structures more resilient.

Regions that have diversified in technologically related sectors, where firms can share complementary know-how, may have an advantage in undertaking and exploiting processes of knowledge recombination within pools of existing knowledge, across pools of old and new knowledge, and arguably in different pools of new knowledge (Boschma \& Iammarino, 2009).

Innovations that arise from recombinant processes can be more successful due to the benefits of past experience: through time, actors learn to identify what elements to recombine, what to leave aside, and what combinations are better than others for specific contexts and strategic objective (Fleming, 2001; Fleming \& Sorenson, 2001). In this process, recombination of related components tends to be associated with lower costs and lower levels of uncertainty of innovation outcomes. Therefore, during times of economic uncertainty proximity in the technology space might be as important as geographical proximity in that it is easier to utilize knowledge inputs that are coherent with one other compared to cognitively distant inputs (Antonelli et al., 2010; Boschma, 2005, 2015; Nooteboom, 2000; Quatraro, 2010). It follows that during economic downturns a region with a comparatively higher number of technologically related activities can exploit more learning opportunities and is more likely to create new growth paths through the recombination of available technological competences (Boschma, Minondo, \& Navarro, 2012). We therefore propose the following hypothesis:

Hypothesis 2: The degree of technological coherence in a region's technology portfolio positively influences its resilience.
In the short run the regional economies' opportunities for path renewal are arguably stronger when a region's industrial structure exhibits a higher degree of related variety and stronger inter-industry learning (Frenken et al., 2007; Sedita et al., 2014). Regions can develop new developmental paths as new activities branch out from existing sectors on the basis of technologically related resources (Boschma, 2015; Kogler et al., 2017). However, there is abundant empirical evidence that industries differ substantially in their innovation patterns, search and appropriability regimes, and demand (Breschi, Malerba, \& Orsenigo, 2000; Malerba, 2004). This implies that the opportunities for growth are not evenly distributed across sectors and that the type of industry specialization can have significant consequences in sustaining aggregate performance (Audretsch, 1995; Diodato \& Weterings, 2015; Glaeser \& Kerr, 2009). Local economies, therefore, might gain competitive advantage by orienting some productive capabilities towards emerging fields and new demand (Suire \& Vicente, 2009). Other things being equal, we expect that regions will tend to be more resilient if they orient their innovative activities towards sectors with the strongest growth opportunities. High-tech sectors are areas of specialization able to provide such growth opportunities even though these might entail greater technology risk (OECD, 2014). This leads one to formulate the following hypothesis:

Hypothesis 3: Innovative activities in high-tech sectors have a positive effect on resilience.

One aspect of this debate that has attracted not only considerable academic scrutiny, but also strong policy interest is the role of entrepreneurship. Entrepreneurs can directly contribute to processes of economic development by identifying and capturing new business opportunities and by converting new knowledge into marketable products (Baumol, 2010; Schumpeter, 1934). New firms can therefore be powerful engines of structural change and positive contributors to strengthen regional economies adaptive capacities (e.g., Audretsch \& Keilbach, 2004; Fritsch, 2013; Haltiwanger, Jarmin, \& Miranda, 2013). ${ }^{3}$ By starting new businesses, entrepreneurs capture locally available knowledge, shape the exploitation of resources in novel or more efficient ways, and in doing so have the potential to sustain local labour markets. New firms have been profiled as a key determinant of regional resilience because they can provide counter-cyclical job opportunities in addition to or away from older businesses that may lack the flexibility to adapt to adverse demand conditions (Martin, 2012; Simmie \& Martin, 2010). This motivates the following hypothesis:

\section{Hypothesis 4: New firm formation has a positive effect on regional resilience.}

While focusing on the role of technological variety, coherence, high-tech activities and new firm formation, we also need to take into account the effect of the region's absorptive capacity, employment specialization and 
agglomeration economies. Adapting Cohen and Levinthal's (1989) approach to a regional context, we refer to absorptive capacity as the region's ability to identify, assimilate and exploit knowledge from the environment. We also control for the relative share of employment in different occupations. Finally, we account for agglomeration effects because the existence of urbanization economies can provide stronger infrastructures for the production, absorption, and exchange of knowledge (Frenken et al., 2007) and the literature has suggested that this can have a significant impact on resilience (Capello, Caragliu, \& Fratesi, 2015; Lee, 2014).

\section{DATA AND VARIABLES}

\section{Data set}

We use information on the employment and economic structure of UK NUTS-III regions combined with information on patent records. The data sources are the National On-line Manpower Information System (NOMIS) portal of the ONS and the EPO's PATSTAT database (from which EUROSTAT extracts information on patents). We consider patent applications submitted to the EPO by inventors resident in the different NUTSIII UK regions. ${ }^{4}$ Following a well-established tradition, we use information contained in patent applications to characterize regional economies since applications as the outcome of research and development $(R \& D)$ investments are good indicators of technological capabilities (Jaffe \& Trajtenberg, 2002). Patent applications are grouped into eight technological classes (each class corresponds to the first digit of the IPC) and 121 subclasses (defined using patent applications with three-digit IPC classes). In the analyses we use patents with three-digit IPC classes. We also include the number of high-tech patents as an indicator of advanced technological capabilities. The trilateral statistical report of the EPO, the Japanese Patent Office (JPO) and the United States Patent and Trademark Office (USPTO) establishes which IPC classes have to be included in this statistic and identifies as relevant fields: aviation, communication technology, computer and automated business equipment, lasers, microorganism and genetic engineering, and semiconductors. ${ }^{5}$ The econometric analysis is carried out with data on 134 UK NUTS-III regions observed over the period 2004-12. This spatial unit of analysis captures at a satisfactory level of disaggregation the dynamics of local economies as theorized in the new economic geography literature as well as research on agglomeration economies (Frenken et al., 2007). The span of the time series is appropriate for our research purposes because it contains the 2008 financial crisis as a major exogenous shock. The final data set is a balanced panel of 1206 observations, with data merged on the basis of NUTS-III regional code and year.

\section{Variables and measures}

Dependent variable

In our empirical analysis, the dependent variable is the degree of resilience displayed by the UK NUTS-III regions throughout the financial downturn that started in 2008. Several authors (Di Caro, 2015; Fingleton et al., 2012; Holm \& Østergaard, 2015; Lee, 2014; Simmie \& Martin, 2010) argue that evaluating differential employment effects is an efficient empirical strategy for the study of adaptive resilience in the wake of exogenous shocks because, following Martin (2012, p. 110):

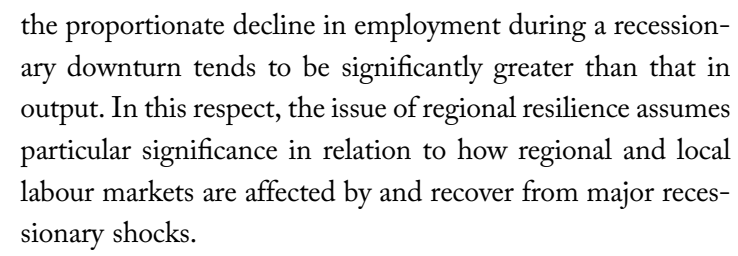

Owing to the non-stationarity of the employment (level) series, following Fingleton et al. (2012), we use as key dependent variable the yearly employment growth rate $\left(g \mathrm{Emp}_{i, t}\right)$ in each NUTS-III $i$ at time $t$.

The variable is calculated over the period $2004-12$ as follows:

$$
g \mathrm{Emp}_{i, t}=\frac{\mathrm{Emp}_{i, t}-\mathrm{Emp}_{i, t-1}}{\mathrm{Emp}_{i, t-1}}
$$

\section{Independent variables}

We want to investigate the effect of different technological profiles on the capacity of regional economies to be resilient to exogenous shocks. More precisely, we are interested in the impact of different degrees and types of technological diversification on resilience. Therefore, we introduce in the estimation different indicators of variety: regional entropy, unrelated variety (UV) and related variety (RV).

Theil originally introduced the information entropy index $(H)$ to economic analysis in 1967 in order to measure the degree of disorder or randomness of a system (Theil, 1967). In its earliest applications, it was used to analyze how different economic activities were distributed between sectors, firms or regions (Attaran, 1986; Boschma \& Iammarino, 2009; Frenken et al., 2007). We use this index as a first measure of the degree of regional technological diversification.

One of the main advantages of this specific measure is that entropy can be decomposed at each technology digit level (Jacquemin \& Berry, 1979; Theil, 1972). We compute the index by using patent data at the three-digit level available for each UK NUTS-III units. Thus, RV is measured at a lower level of aggregation (three-digit class within a onedigit section) than UV (across one-digit section). The first measure captures the average degree of disorder or variety within the subsets, while the second captures the degree of randomness between the higher order sections.

Formally, we define $I=(1, \ldots, n)$ as the set containing all 121 patent IPC subclasses ' $i$ ' (three-digit technology code). Additionally, $G=(1, \ldots, g)$ is the set including the eight technological sections of the IPC standard classification ' $g$ ' (one-digit technology code). Following the IPC standard classification scheme all the patent subclasses 
$i=1, \ldots, N$ in our database fall exclusively under a unique technological section $S_{g}$, where $g=1, \ldots, G$. Thus, each of the 121 patent subclasses can be grouped into one of eight technological sections of the IPC standard classification. Along these lines, if we admit that each subclass $i$ pertains exclusively to one technological section $g$, then we may compute the probability of one patent having the classification $g\left(P_{g}\right)$ as the summation of probabilities of all subclasses $i$ within $g$. Formally:

$$
P_{g}=\sum_{i \in S_{g}} p_{i}
$$

where $p_{i}$ is the number of patents in the three-digit subclass $i$ within $g$.

Therefore, the between-group entropy or UV measured between patent sections is calculated as follows:

$$
U V=\sum_{g=1}^{G} P_{g} \log _{2}\left(\frac{1}{P_{g}}\right)
$$

The entropy decomposition theorem specifies that the relation between $\mathrm{UV}$ and the regional total information entropy can be defined as follows:

$$
H=U V+\sum_{g=1}^{G} P_{g} H_{g}
$$

where RV or within-group entropy represents the second part of the equation:

$$
\begin{gathered}
R V=\sum_{g=1}^{G} P_{g} H_{g} \\
H_{g}=\sum_{i \in S_{g}} \frac{p_{i}}{P_{g}} \log _{2}\left(\frac{1}{\frac{p_{i}}{P_{g}}}\right)
\end{gathered}
$$

The total entropy measure is heavily influenced by the relative dynamics of RV and UV. If the effect of unrelated technological variety is dominant, the effects of total entropy on resilience, measured as yearly variation in the employment rate, is expected to be negative. The index has a positive effect on regional adaptability if related technological variety plays a predominant role because it fosters spillovers that feed more efficiently into processes of knowledge recombination (Boschma, 2005; Nooteboom, Van Haverbeke, Duysters, Gilsing, \& Van den Oord, 2007; Plum \& Hassink, 2014). One drawback of the information entropy index $(H)$ is that it is highly dependent on the IPC hierarchical classification and therefore both RV and UV may fail to capture epistemic proximity between different groups of patents. Several studies (e.g., Boschma, Minondo, \& Navarro 2012; Content \& Frenken, 2016) highlighted that RV could be a weak measure of relatedness, despite the broad application this index has found in the empirical literature, because it relies on an ex-ante classification scheme that does not reflect the 'true' proximity of technological capabilities.
In order to obtain a measure of the average epistemic relatedness of any technology randomly chosen within a region with respect to any other technology (Nesta \& Saviotti, 2005, 2006) we calculate a regional technological coherence index (Coherence). It allows one to evaluate the extent of regional diversification while taking into account the volume of patenting activities in different classes weighted by their degree of technological proximity. This method derives relatedness ex-post from data rather than ex-ante from a classification scheme. ${ }^{6}$ The value of Coherence is calculated as follow. First, we compute the coherence index $\left(\tau_{i j}\right)$ introduced by Teece, Rumelt, Dosi, and Winter (1994). Our universe is made of 134 NUTS-III regions each patenting in the period 2004-12 in two or three technological fields (IPC classification). If region $k$ is active in technological field $i G_{i k}=1$, otherwise $G_{i k}=0$. Therefore, the total number of regions active in technology $i$ is equal to $K_{i}=\sum G_{i k}$. In the same fashion the number of regions patenting both in the fields $i$ and $j$ is computed as follows: $O_{i j}=\sum_{k} G_{i k} G_{j k}$. By applying this formula to all possible pairs of technological fields we obtain a square $(8 \times 8)$ symmetrical matrix $\Omega$, in which the generic cell $O_{i j}$ records the number of regions that each year (from 2004 to 2012) were active in both technological fields $i$ and $j$. The $\tau_{i j}$ is computed as a 'test of randomness' that compares the observed value of $O_{i j}$ with the value that would be expected under the hypothesis that technological diversification is random (Nesta \& Saviotti, 2005; Bryce \& Winter, 2009):

$$
\tau_{i j}=\frac{O_{i j}-\mu_{i j}}{\sigma_{i j}}
$$

where $\mu_{i j}$ is the mean of the counterfactual random sample $X_{i j}$ :

$$
\mu_{i j}=E\left(X_{i j}\right)=\frac{K_{i} K_{j}}{K}
$$

and $\sigma_{i j}^{2}$ is the variance:

$$
\sigma_{i j}^{2}=\mu_{i j}\left(1-\frac{K_{i}}{K}\right)\left(\frac{K-K_{j}}{K-1}\right)
$$

where $K$ represents the total number of NUTS-III regions included in our sample.

On this basis we proceed to calculate the weighted average relatedness, $W A R_{j k}$, of technology $j$ with respect to all other $m$ technologies present within the region $k$ :

$$
W A R_{j k}=\frac{\sum_{m \neq j} \tau_{j m} P_{m k}}{\sum_{m \neq j} P_{m k}}
$$

where $W A R_{j k}$ is defined as the degree to which technology $j$ is related to all other technologies $m \neq j$ within the region $k$ weighted by the number of patent $P_{m k}$ of technology $m$ in the specific NUTS-III region. Finally, the regional technological coherence $(C)$ of region $k$ is defined as the weighted 


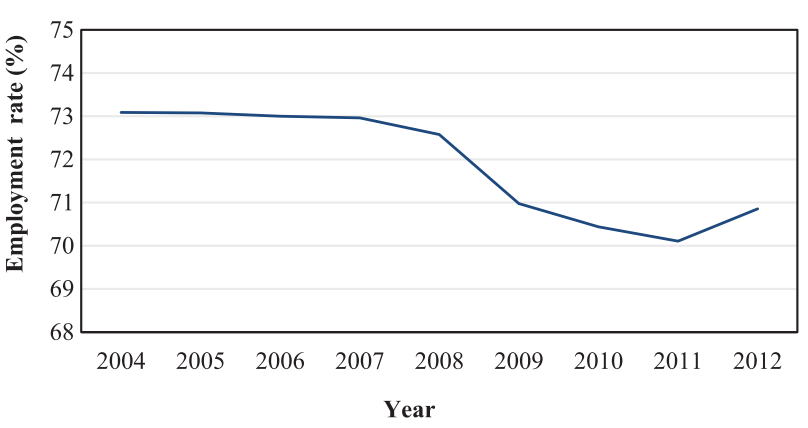

Figure 1. Evolution of UK employment, 2004-12.

Sources: National On-line Manpower Information System (NOMIS) PATSTAT and authors' own calculations.

average of the $W A R_{j k}$ :

$$
\text { Coherence }_{k}=\sum_{j} W A R_{j k} \frac{P_{j k}}{\sum_{j} P_{j k}}
$$

where $\sum_{j} P_{j k}$ is the total number of patents within the region $k$ (NUTS-III).

This measure captures the degree to which the different classes of patents making up the technological knowledge base of a region are complementary to one another. This renders the coherence index particularly appropriate for our research objectives. We expect that this index will be positively related to regional resilience since, as explained above, we conjecture that technological proximity plays a key role in prompting recombinant growth processes within regions.

We include among the focal determinants of resilience the ability of a region to innovate in newer technological fields and new firm formation. These two variables are defined as follow. Employing the data on the number of patents filed in high-tech sectors for each NUTS-III region we construct the variable high-tech patents (HT_pat) to capture the extent of innovation in technologies associated with the strongest growth opportunities. Following the EPO, JPO and USPTO's indication, these are aviation, communication technology, computer and automated business equipment, lasers, microorganism and genetic engineering, and semiconductors. ${ }^{7}$

The variable Entry measures the rate at which new firms appear in the local economy. New firm formation has been extensively used in the literature on the relationship between entrepreneurship and regional growth (e.g., Acs \& Armington, 2004; Audretsch \& Fritsch, 2002; Baptista, Escaria, \& Madruga, 2008; Doran, McCarthy, \& O'Connor, 2016; Fritsch \& Mueller, 2004). We use it to identify the effect of entrepreneurship on resilience and calculate it as the year-on-year growth rate of the number of firms active in each NUTS-III units. The expectation derived from theory is that regions endowed with more new firms are better prepared to face unforeseen shocks and display resilience.

We include controls for other regional characteristics, such as education levels of the workforce and population density. We use the share of employees with the lowest level of education for each NUTS-III region (that is the number of workers with National Vocational Qualifications - NVQ) to measure weak absorptive capacity. ${ }^{8} \mathrm{We}$ expect that a larger share of lower education levels will negatively influence regional resilience. Moreover, to account for patterns of specialization in the regional employment we compute an index equal to the ratio between the share of employment in elementary occupations and the share of science and technology-related jobs ( $\left.L T_{-} j o b s\right)$. Regions with a comparatively weaker specialization in high-tech jobs are less likely to engage in those cutting-edge innovation processes that are likely to make the region more resilient to downturns. Population density (Density) is finally added as a proxy for the agglomeration patterns of UK NUTS-III micro-regions as in Frenken et al.'s (2007) study.

The dummy variable Crisis enters the econometric analysis to assess the role of the 'Great Recession' and more specifically to test how the structure of local technological knowledge mediates the effect of the downturn. When we look at the main trend in employment (Figure 1)

Table 1. Descriptive statistics (whole sample).

\begin{tabular}{|c|c|c|c|c|c|c|}
\hline & & Observations & Mean & SD & Minimum & Maximum \\
\hline gEmp & Employment growth & 1072 & -0.004 & 0.03 & -0.11 & 0.12 \\
\hline Entropy & Variety & 1206 & 3.16 & 1.18 & 0.00 & 5.21 \\
\hline$R V$ & Related variety & 1206 & 1.14 & 0.62 & 0.00 & 2.59 \\
\hline UV & Unrelated variety & 1206 & 2.02 & 0.67 & 0.00 & 2.92 \\
\hline Coherence & Coherence & 1164 & 3.95 & 0.68 & 0.00 & 8.59 \\
\hline HT pat & Number of patents in high-tech & 982 & 10.01 & 20.20 & 0.00 & 180.48 \\
\hline Entry & Growth rate of the number of new firms & 1072 & 0.14 & 0.19 & -0.85 & 5.96 \\
\hline NVQ & Share of low educated employees & 1204 & 7.93 & 3.57 & 0.70 & 24.00 \\
\hline$L T$ jobs & $\begin{array}{l}\text { Ratio between employment in elementary and } \\
\text { in science and technology jobs }\end{array}$ & 1206 & 1.47 & 0.21 & 0.207 & 10.62 \\
\hline Density & Population density & 1206 & 1245.50 & 1694.92 & 7.10 & 10,391 \\
\hline Crisis & Dummy crisis & 1206 & 0.44 & 0.50 & 0.00 & 1.00 \\
\hline
\end{tabular}


for the period 2004-12 it is evident that the financial crisis of 2008 had a severe effect on the British job market in 2009. The year 2012 marked a reversal of the recessionary trend but did not bring employment back on a par with the pre-crisis period. ${ }^{9}$ The variable Crisis is defined as 0 until and including the year 2008 and 1 afterwards.

\section{DESCRIPTIVE STATISTICS}

Table 1 provides the descriptive statistics for the whole data set and Table 2 shows the correlation matrix. Generally, correlation levels are low. The only variables significantly correlated with each other are $H, R V$ and $U V$ because of the way these indices are constructed ( $H$ results from the sum of $R V$ and $U V)$. We need to keep this in mind when we estimate the model.

The growth rate of employment over the period 200412 is on average largely negative and just 49 out of 134 British micro-regions registered a moderately positive change in their employment performance. When we compare the pre-crisis and crisis periods, we detect significant unevenness: Figure 2 shows how regions with positive growth are much more numerous in the first relative to the second period, that persistent growth across periods is rare, and that the crisis period (on the right-hand side) is associate with more areas of markedly negative growth among the Northern regions. These differences will be investigated in detail in the econometric analysis that follows.

\section{ECONOMETRIC ANALYSIS AND FINDINGS}

To investigate the effects of different technological profiles on resilience, and to evaluate at the same time the 'within' and 'between' variation of the micro-regions, we use a pooled ordinary least squares (OLS) model. Complementary fixed effect models (Table 3), which help to account for potential unobserved heterogeneity, fully confirm the results.

In the estimations, we adopt a stepwise approach: first, we estimate a model designed to explain the regional variation in employment within regions and across regions; and second, in order to evaluate how the regional technological structure mediates the effect of the recession, we interact the dummy variable for the crisis period (defined as 0 until and including the year 2008, 1 afterwards) with the focal determinants of resilience.

The baseline model we use takes the form:

$$
\begin{aligned}
g \operatorname{Emp}_{i, t}= & \beta_{0}+\beta_{1} \text { entropy }_{i, t-1} \\
& +\beta_{2} \text { Coherence }_{i, t-1}+\beta_{3} H T{\text { - } \text { pat }_{i, t-2}} \\
& +\beta_{4} \text { entry }_{i, t-1}+\beta_{5} N V Q_{i, t-1} \\
& +\beta_{6} L T \text { jobs }_{i, t-1}+\beta_{7} \text { density }_{i, t-1} \\
& +\beta_{8} \text { crisis }_{i, t}+u_{i, t}
\end{aligned}
$$

where $g \mathrm{Emp}_{i, t}$ represents the variation in the employment rate of region $i$ from year $t$ to year $t-1$. All explanatory variables are lagged by one period, with the exception of

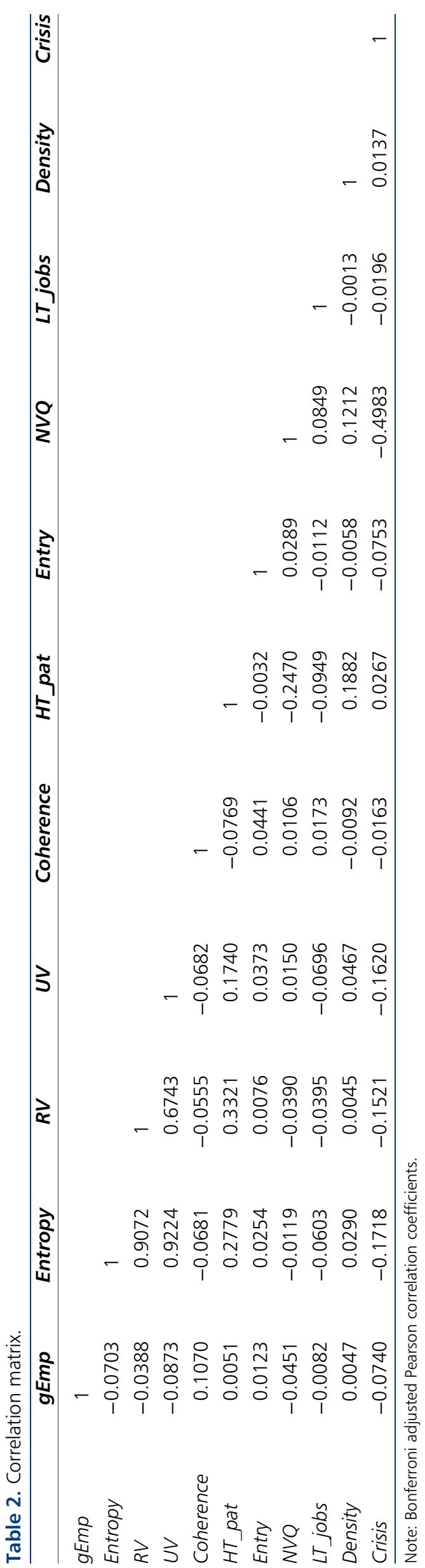




\section{Employment growth, 2004-08}

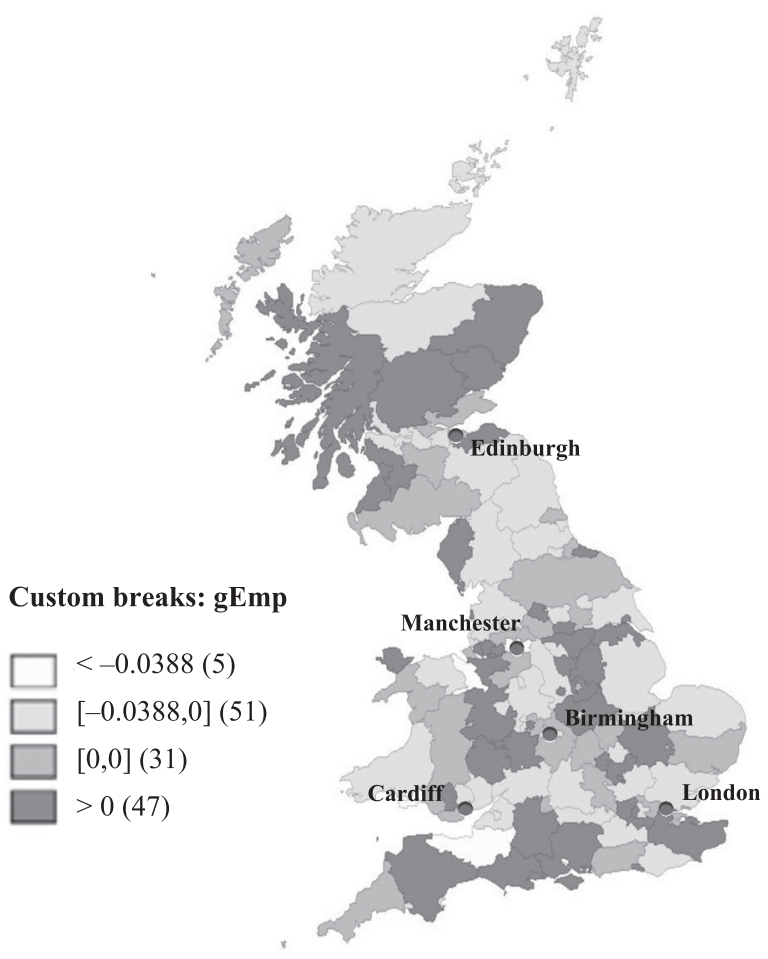

\section{Employment growth, 2009-12}

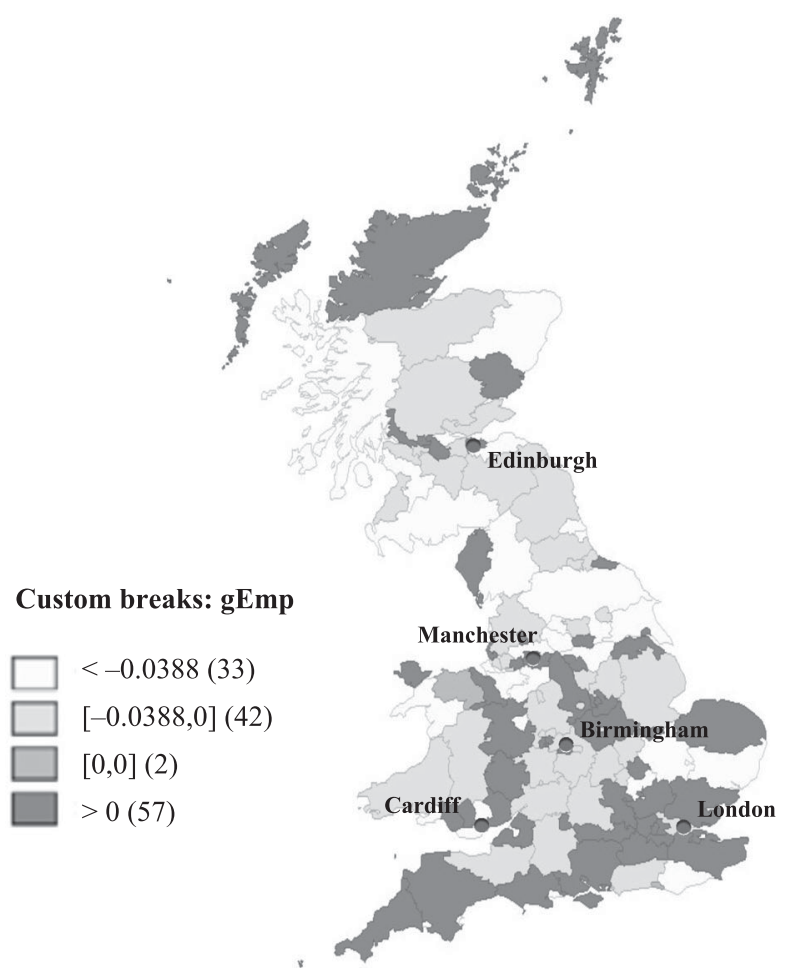

Figure 2. Employment growth across UK regions in pre-crisis (left) and crisis (right) years (period averages). Sources: National On-line Manpower Information System (NOMIS) PATSTAT and authors' own calculations.

the variable high-tech patents (HT_pat): this is lagged by an additional year to reflect more accurately the lags of the patenting process (Griliches, Pakes, \& Hall, 1987). As already noticed in commenting on Table 2 , the variables Entropy, $R V$ and $U V$ are highly correlated. Therefore, they enter the estimations separately and in a stepwise manner.

In order to evaluate how the regional technological structure moderates the effect of the financial crisis - and therefore to test the determinants of regional resilience to this shock - we then interact key explanatory variables (Coherence, Entropy, RV, UV, HT_pat and Entry) with the crisis period dummy. Thus, this second model takes the form:

$$
\begin{aligned}
g \mathrm{Emp}_{i, t}= & \beta_{0}+\beta_{1} \text { entropy }_{i, t-1}+\beta_{2} \text { Coherence }_{i, t-1} \\
& +\beta_{3} H \text { T.pat }_{i, t-2}+\beta_{4} \text { entry }_{i . t-1} \\
& +\beta_{5} N V Q_{i, t-1}+\beta_{6} L T \text { jobs }_{i, t-1}+\beta_{7} \text { density }_{i, t-1} \\
& +\beta_{8} \text { crisis }_{i, t}+\beta_{9} \text { entropy }_{i, t-1} \text { crisis }_{i, t} \\
& +\beta_{10} \text { Coherence }_{i, t-1} * \text { crisis }_{i, t}+\beta_{3} H T_{- \text {pat }_{i, t-2}} \\
& * \text { crisis }_{i, t}+\beta_{12} \text { entry }_{i . t-1} * \text { crisis }_{i, t}+u_{i, t}
\end{aligned}
$$

Table 4 reports the results of the estimations that alternatively include Entropy (column 1), $R V$ (column 2) and UV (column 3).
As far as the variables Entropy, $R V$ and $U V$ are concerned, the results of the baseline estimations show that their coefficient is insignificant. Thus, in contrast with evidence found in previous literature all the measures of diversification appear to have no effect on employment growth. Regional technological coherence (Coherence) has instead a positive and significant coefficient in all estimations. This result suggests that diversifying in technological coherent patent classes is a fundamental determinant of employment creation. It also shows that, in line with previous literature, the effect of low skills employment $(N V Q)$ is negative and statistically significant in all the estimations, which means that greater shares of low skilled employees make the regional economy less able to improve their occupational profile. New firm formation (the variable Entry) has insignificant (negative) coefficients. Finally, these results indicate that, as expected, the recession (Crisis) had an important negative influence on job growth.

The results of the interacted model highlight that all measures of diversification show a negative but insignificant coefficient. As we find that the portfolio diversification is not affecting adaptive resilience, Hypothesis 1 is not confirmed. Coherence and high-tech patents (HT_pat) exhibit instead positive and significant coefficients in all estimations, demonstrating that the sources of resilience are to be found in the technological coherence of the regional economy and in its orientation towards innovation in sectors associated with the strongest technological 
Table 3. Results of fixed effects estimation.

\begin{tabular}{|c|c|c|c|c|c|c|}
\hline \multirow[b]{2}{*}{ Dependent variable: $g E m p$} & \multicolumn{3}{|c|}{ Baseline } & \multicolumn{3}{|c|}{ Interacted } \\
\hline & (1) & $(2)$ & (3) & $(1)$ & $(2)$ & (3) \\
\hline \multirow[t]{2}{*}{ Entropy } & -0.000190 & & & 0.00274 & & \\
\hline & $(0.00264)$ & & & $(0.00281)$ & & \\
\hline \multirow[t]{2}{*}{$R V$} & & -0.00356 & & & -0.000700 & \\
\hline & & $(0.00373)$ & & & $(0.00401)$ & \\
\hline \multirow[t]{2}{*}{ UV } & & & 0.00395 & & & 0.0100 \\
\hline & & & $(0.00416)$ & & & $(0.00470)$ \\
\hline \multirow[t]{2}{*}{ Coherence } & $0.0250 * *$ & $0.0255^{* *}$ & $0.0250 * *$ & 0.00352 & 0.00583 & 0.00318 \\
\hline & $(0.00891)$ & $(0.00891)$ & $(0.00890)$ & $(0.00913)$ & $(0.00902)$ & $(0.00907)$ \\
\hline \multirow[t]{2}{*}{ HT pat } & 0.000647 & 0.000646 & 0.000722 & -0.000345 & -0.000274 & -0.000203 \\
\hline & $(0.00152)$ & $(0.00151)$ & $(0.00152)$ & $(0.00148)$ & $(0.00148)$ & $(0.00147)$ \\
\hline \multirow[t]{2}{*}{ Entry } & -0.00572 & -0.00575 & -0.00608 & -0.00397 & -0.00384 & -0.00449 \\
\hline & $(0.00463)$ & $(0.00462)$ & $(0.00463)$ & $(0.00446)$ & $(0.00446)$ & $(0.00446)$ \\
\hline \multirow[t]{2}{*}{$N V Q$} & $-0.00203^{* *}$ & $-0.00200 * *$ & $-0.00203^{* *}$ & 0.000225 & 0.000178 & 0.000245 \\
\hline & $(0.000760)$ & $(0.000760)$ & (0.000759) & (0.000778) & (0.000778) & $(0.000775)$ \\
\hline \multirow[t]{2}{*}{$L T$ jobs } & -0.000488 & -0.000475 & -0.000503 & -0.000518 & -0.000453 & -0.000539 \\
\hline & $(0.000640)$ & (0.000639) & $(0.000639)$ & $(0.000614)$ & $(0.000613)$ & $(0.000612)$ \\
\hline \multirow[t]{2}{*}{ Density } & 0.0000172 & 0.0000170 & 0.0000169 & 0.00000883 & 0.00000902 & 0.00000856 \\
\hline & $(0.0000212)$ & $(0.0000212)$ & $(0.0000212)$ & (0.0000209) & $(0.0000210)$ & $(0.0000209)$ \\
\hline \multirow{2}{*}{ Crisis } & $-0.00612^{*}$ & $-0.00615^{*}$ & $-0.00606^{*}$ & $-0.0198 * * *$ & $-0.0197 * * *$ & $-0.0200 * * *$ \\
\hline & $(0.00264)$ & $(0.00264)$ & $(0.00264)$ & $(0.00310)$ & $(0.00310)$ & $(0.00310)$ \\
\hline \multirow[t]{2}{*}{ Entropy *crisis } & & & & -0.00391 & & \\
\hline & & & & $(0.00241)$ & & \\
\hline \multirow[t]{2}{*}{$R V^{*}$ crisis } & & & & & -0.00458 & \\
\hline & & & & & $(0.00398)$ & \\
\hline \multirow[t]{2}{*}{$U V^{*}$ crisis } & & & & & & -0.00870 \\
\hline & & & & & & $(0.00463)$ \\
\hline \multirow[t]{2}{*}{ Coherence ${ }^{*}$ crisis } & & & & $0.0266^{* * *}$ & $0.0206^{* * *}$ & $0.0310 * * *$ \\
\hline & & & & $(0.00682)$ & $(0.00453)$ & $(0.00814)$ \\
\hline \multirow[t]{2}{*}{ HT pat* crisis } & & & & $0.00288^{*}$ & $0.00271 *$ & $0.00271 *$ \\
\hline & & & & $(0.00134)$ & (0.00135) & $(0.00131)$ \\
\hline \multirow[t]{2}{*}{ Entry* ${ }^{*}$ risis } & & & & -0.0449 & -0.0466 & -0.0426 \\
\hline & & & & $(0.0319)$ & $(0.0319)$ & $(0.0318)$ \\
\hline Regional dummies & Yes & Yes & Yes & Yes & Yes & Yes \\
\hline \multirow[t]{2}{*}{ Constant } & -0.0388 & -0.0353 & -0.0482 & -0.00707 & 0.00105 & -0.0200 \\
\hline & $(0.0317)$ & $(0.0307)$ & $(0.0318)$ & $(0.0311)$ & $(0.0302)$ & $(0.0313)$ \\
\hline$R^{2}$ & 0.09 & 0.08 & 0.08 & 0.13 & 0.13 & 0.14 \\
\hline Observations & 747 & 747 & 747 & 747 & 747 & 747 \\
\hline Regions & 131 & 131 & 131 & 131 & 131 & 131 \\
\hline
\end{tabular}

Note: Estimated intercept and slope coefficients for each regressor with robust standard errors in parentheses. ${ }^{*} p<0.05,{ }^{* *} p<0.01,{ }^{* * *} p<0.001$.

opportunities. This is clear evidence in support of Hypotheses 2 and 3. The variable Entry also has a non-significant effect on resilience. Contrary to our expectations (Hypothesis 4), the results suggest that new firms per se do not have any effect on the resilience of regions. ${ }^{10}$

As a further robustness check we repeat the estimations by using an alternative measure of variety. We include in both regressions a new measure of diversification $\left(D_{i v_{i, t}}\right)$ which is equal to the fractionalization index proposed by Alesina, Devleeschauwer, Easterly, Kurlat, and Wacziarg (2003):

$$
\operatorname{Div}_{i, t}=1-\text { Herfindahl }_{i, t}
$$

A low index value means that patents within the NUTS-III region are concentrated in a few patent classes. Conversely, a higher value indicates greater variety in the distribution of 
Table 4. Results of the pooled ordinary least squares (OLS) estimations.

\begin{tabular}{|c|c|c|c|c|c|c|}
\hline \multirow[b]{2}{*}{ Dependent variable: $g E m p$} & \multicolumn{3}{|c|}{ Baseline } & \multicolumn{3}{|c|}{ Interacted } \\
\hline & (1) & $(2)$ & (3) & (1) & $(2)$ & (3) \\
\hline \multirow[t]{2}{*}{ Entropy } & -0.000190 & & & 0.00231 & & \\
\hline & $(0.00264)$ & & & $(0.00270)$ & & \\
\hline \multirow[t]{2}{*}{$R V$} & & -0.00356 & & & -0.000836 & \\
\hline & & $(0.00373)$ & & & $(0.00397)$ & \\
\hline \multirow[t]{2}{*}{ UV } & & & 0.00395 & & & 0.00863 \\
\hline & & & $(0.00416)$ & & & $(0.00449)$ \\
\hline \multirow[t]{2}{*}{ Coherence } & $0.0250 * *$ & $0.0255^{* *}$ & $0.0250 * *$ & 0.00144 & 0.00474 & -0.000419 \\
\hline & $(0.00891)$ & $(0.00891)$ & $(0.00890)$ & $(0.00834)$ & $(0.00807)$ & $(0.00831)$ \\
\hline \multirow[t]{2}{*}{ HT pat } & 0.000647 & 0.000646 & 0.000722 & -0.000410 & -0.000306 & -0.000317 \\
\hline & $(0.00152)$ & $(0.00151)$ & $(0.00152)$ & $(0.00147)$ & $(0.00147)$ & $(0.00147)$ \\
\hline \multirow[t]{2}{*}{ Entry } & -0.00572 & -0.00575 & -0.00608 & -0.00385 & -0.00380 & -0.00423 \\
\hline & $(0.00463)$ & $(0.00462)$ & $(0.00463)$ & $(0.00445)$ & $(0.00445)$ & $(0.00445)$ \\
\hline \multirow[t]{2}{*}{$N V Q$} & $-0.00203^{* *}$ & $-0.00200 * *$ & $-0.00203^{* *}$ & 0.000102 & 0.000119 & 0.0000182 \\
\hline & $(0.000760)$ & $(0.000760)$ & (0.000759) & $(0.000746)$ & $(0.000746)$ & $(0.000740)$ \\
\hline \multirow[t]{2}{*}{$L T$ jobs } & -0.000488 & -0.000475 & -0.000503 & -0.000542 & -0.000467 & -0.000579 \\
\hline & $(0.000640)$ & (0.000639) & (0.000639) & $(0.000613)$ & $(0.000611)$ & $(0.000611)$ \\
\hline \multirow[t]{2}{*}{ Density } & 0.0000172 & 0.0000170 & 0.0000169 & -0.0000172 & -0.0000132 & -0.0000232 \\
\hline & $(0.0000212)$ & $(0.0000212)$ & $(0.0000212)$ & $(0.0000147)$ & $(0.0000141)$ & $(0.0000147)$ \\
\hline \multirow[t]{2}{*}{ Crisis } & $-0.00612^{*}$ & $-0.00615^{*}$ & $-0.00606^{*}$ & $-0.0201 * * *$ & $-0.0199 * * *$ & $-0.0205^{* * *}$ \\
\hline & $(0.00264)$ & $(0.00264)$ & $(0.00264)$ & $(0.00305)$ & $(0.00304)$ & $(0.00305)$ \\
\hline \multirow[t]{2}{*}{ Entropy*crisis } & & & & -0.00385 & & \\
\hline & & & & $(0.00241)$ & & \\
\hline \multirow[t]{2}{*}{$R V^{*}$ crisis } & & & & & -0.00460 & \\
\hline & & & & & $(0.00397)$ & \\
\hline \multirow[t]{2}{*}{$U V^{*}$ crisis } & & & & & & -0.00818 \\
\hline & & & & & & $(0.00460)$ \\
\hline \multirow[t]{2}{*}{ Coherence ${ }^{*}$ crisis } & & & & $0.0265^{* * *}$ & $0.0206^{* * *}$ & $0.0303 * * *$ \\
\hline & & & & $(0.00681)$ & $(0.00452)$ & $(0.00810)$ \\
\hline \multirow[t]{2}{*}{ HT pat* ${ }^{*}$ crisis } & & & & $0.00299 *$ & $0.00277^{*}$ & $0.00289 *$ \\
\hline & & & & $(0.00132)$ & $(0.00133)$ & $(0.00129)$ \\
\hline \multirow[t]{2}{*}{ Entry* ${ }^{*}$ risis } & & & & -0.0441 & -0.0462 & -0.0413 \\
\hline & & & & $(0.0318)$ & $(0.0318)$ & $(0.0318)$ \\
\hline Regional dummies & Yes & Yes & Yes & Yes & Yes & Yes \\
\hline \multirow[t]{2}{*}{ Constant } & -0.0408 & -0.0371 & -0.0493 & & & \\
\hline & $(0.0286)$ & $(0.0277)$ & $(0.0285)$ & & & \\
\hline$R^{2}$ & 0.12 & 0.12 & 0.12 & 0.22 & 0.22 & 0.22 \\
\hline Observations & 747 & 747 & 747 & 747 & 747 & 747 \\
\hline Regions & 131 & 131 & 131 & 131 & 131 & 131 \\
\hline
\end{tabular}

Note: Estimated intercept and slope coefficients for each regressor with robust standard errors in parentheses. ${ }^{*} p<0.05$, ${ }^{* *} p<0.01,{ }^{* * *} p<0.001$.

regional patents among different classes. The results (reported in Table A2 in Appendix A of the supplemental data online) validate our approach and previous results. ${ }^{11}$

\section{CONCLUSIONS}

We began this study by reflecting on the unevenness with which different UK regions reacted to the 2008 financial crisis and we set out to explore what aspects of a regional economy drive stronger performances against a recessionary shock. While much research exists on the drivers of regional growth, the question arises whether the factors that foster growth are the same as those that enhance the ability of a region to fence off the negative effects of a crisis. Moreover, despite the emphasis placed by the literature on the importance of regional technological capabilities, relatively few studies had considered the technological profiles of regions as determinants of resilience. The contribution 
of this paper is therefore threefold: first, we enrich the theorization of resilience by stressing its deep connection with different types of technological diversification; second, we operationalize an empirical test of resilience that can be replicated in different contexts and timeframes; and third, we provide novel empirical evidence that singles out the role of technological coherence, measured through an $e x-$ post frequency-based index of broad applicability to the study of regions.

In testing the role of technological coherence, we find that its effects on resilience are very pronounced, whereas the role of entropy is negligible. Furthermore, we find that high-tech patenting plays a positive and statistically significant role, but - contrary to expectations - new firm formation does not. Coherence generates the strongest results of the model, indicating that in the presence of higher uncertainty or greater resource constraints - two factors typically associated with financial crises - more coherent knowledge bases are conduits of superior performances during recessionary phases of the business cycle. This could be due to the fact that higher cognitive proximity between knowledge inputs favours interacting learning under time of resource constraints. The findings also imply that a high degree of entropy may not generate sufficient returns in the short run, possibly due to higher transaction costs, while it may be easier and more costeffective to utilize a combination of whose joint use is more frequent.

The study has, of course, its limitations. First, these results are generated within one national context (the UK) and further international comparative evidence is needed to generalize them with confidence across countries. Second, we explore the sources of resilience as the short-run reaction of regional economic systems to the financial crisis: it is possible that the drivers of longterm recovery might be different. Only more year-observations will be able to produce insights on this particular aspect of regional growth paths and their evolution through time. Third, our empirical research on the determinants of resilience should be complemented by detailed case study work: this would make it possible to appreciate the nuances of resilience processes and the role of local specificities within the complex network of relationships that characterize regional economic systems.

Finally, a more detailed treatment of entrepreneurial dynamics might allow one to disentangle from one another the effects of different types of entrepreneurship. Our findings indicate that in the process of regional development, the innovativeness of regional economic systems is more important than their capacity to generate new ventures per se. It is possible that new firm formation could have an effect that is contingent on the regional technological bases and we ran additional estimations to test for the combined effect (three-way interactions) of entry, knowledge intensity and the crisis dummy. These estimations did not produce statistically significant results. ${ }^{12}$ There might be different explanations for this. The first explanation is that it might take longer for entrepreneurship to have a positive impact on jobs relative to other variables and this effect will be observable at a later stage of the recovery process, as suggested by Kitsos and Bishop (2016). The second explanation is in line with the view that only a minority of firms are responsible for the creation of new jobs (Haltiwanger et al., 2013). These firms are relatively rare, and while the generation of any such new firm will benefit the regional economy, the addition of an 'average' firm will have no positive net effect (Nightingale \& Coad, 2014; Shane, 2009). Only firm-level microeconomic evidence will be able to shed a light on this particular problem.

Overall, and despite its limitations, the paper has significant policy implications. The results point to the importance of building coherent portfolios of technological capabilities and to the strategic role of innovative activities in high-tech sectors to ensure regions against the negative effects of a recession. Policies that aim to foster resilience should begin by careful assessments of the technological composition of local economic systems. The identification of specific areas of expertise is important to devise the most appropriate incentive schemes and to design innovation policies directed towards the generation of coherent new knowledge with strong elements of innovation at the frontier. This is consistent, for example, with smart specialization policies and place-based approaches to innovation policy. Bearing also this policy agenda in mind, further extensions of our study could address directly the effect of targeted policy interventions on the structure and composition of regional technological profiles - including their degree of coherence - and assess their relative impact of growth and productivity.

\section{ACKNOWLEDGEMENTS}

The authors thank Dieter Kogler, Alessandra Faggian, Andrea Morrison, the CBR team in Cambridge, and the faculty and doctoral students at the Department of Economics and Statistics 'Cognetti de Martiis', Turin. They are grateful to the editor and two anonymous referees for comments, criticisms and suggestions. The paper also benefited greatly from feedback received from the participants and discussants at the 56th ERSA Congress, Eurkind GCW 2016 Conference, the DRUID 2017 Conference, and at research seminars at the University of Turin, University of Birmingham and University College Dublin.

\section{DISCLOSURE STATEMENT}

No potential conflict of interest was reported by the authors.

\section{FUNDING}

The authors gratefully acknowledge funding from the European Research Council under the European Union's Horizon 2020 research and innovation programme [grant agreement number 715631, TechEvo]. 


\section{NOTES}

1. For an in-depth discussion of the notions of resilience and equilibrium in dynamic economic systems, see Reggiani et al. (2002).

2. There are no systematic quantitative data on all these factors, and this underlines the importance of complementary qualitative accounts of resilience generated through a case-study approach to resilience processes in specific local contexts.

3. Van Praag and Versloot (2007), Fritsch (2013) and Doran et al. (2016) provide extensive reviews of this research stream.

4. In the PATSTAT database, patent applications are counted according to the year in which they are filed. Moreover, they are assigned to a country/region on the basis of the inventor's place of residence, using fractional counting if there are multiple inventors for a single patent. We downloaded the data from EUROSTAT regional statistics in autumn 2015.

5. Source: EUROSTAT, High-tech patent applications to the European patent office (EPO) by priority year (http://ec.europa.eu/eurostat/web/products-datasets/-/ tsc00010). Information jointly produced by the patent offices with arguably the strictest scrutiny (EPO, JPO and USPTO) teases out of the 'noisy' population of patent data more precise indications of patents of higher quality and its use is well established in the literature (Nagaoka, Motohashi, \& Goto, 2010; Picard \& van Pottelsberghe de la Potterie, 2011).

6. Since Hidalgo, Klinger, Barabasi, and Hausmann's (2007) seminal work, the evolutionary economic geography literature has used different data sets and methods based on co-occurrence matrices to calculate relatedness (e.g., Kogler et al., 2017; Neffke, Henning, \& Boschma, 2011). As the present paper focuses on how the technological profile of regions shapes resilience, we constructed our co-occurrence matrix using patent data. This makes it possible to capture the degree of technological proximity underlying regional industrial structures following the method indicated by Jaffe (1986) and Breschi, Lissoni, and Malerba (2003).

7. See note 4 .

8. Using inverse measures reduces the risk of multicollinearity in the estimation while capturing the relative effects of high and low absorptive capacities of regional labour markets.

9. Robustness checks performed on our econometric model by excluding the year 2012 from the sample do not change the results.

10. The results of robust estimations (shown in Table A1 in Appendix A in the supplemental data online) are entirely consistent.

11. We ran an additional set of estimations with a measure of coherence based on three-digit IPC classes: these results, available from the authors upon request, are also fully consistent.

12. Results are reported in Table A3 in Appendix A in the supplemental data online.

\section{REFERENCES}

Acs, Z., \& Armington, C. (2004). Employment growth and entrepreneurial activity in cities. Regional Studies, 38, 911-927. doi:10.1080/0034340042000280938

Alesina, A., Devleeschauwer, A., Easterly, W., Kurlat, S., \& Wacziarg, R. (2003). Fractionalization. Journal of Economic Growth, 8(2), 155-194. doi:10.1007/s00191-004-0228-6

Antonelli, C., Krafft, J., \& Quatraro, F. (2010). Recombinant knowledge and growth: The case of ICTs. Structural Change and Economic Dynamics, 21(1), 50-69. doi:10.1016/j.strueco.2009. 12.001

Attaran, M. (1986). Industrial diversity and economic performance in U.S. areas. Annals of Regional Science, 20, 44-54. doi:10.1007/ BF01287240

Audretsch, D. B. (1995). Innovation and industry evolution. Cambridge, MA: MIT Press.

Audretsch, D. B., \& Fritsch, M. (2002). Growth regimes over time and space. Regional Studies, 36, 113-124. doi:10.1080/ 00343400220121909

Audretsch, D. B., \& Keilbach, M. (2004). Entrepreneurship and regional growth: An evolutionary interpretation. Journal of Evolutionary Economics, 14, 605-616. doi:10.1007/s00191-0040228-6

Baptista, R., Escaria, V., \& Madruga, P. (2008). Entrepreneurship, regional development and job creation: The case of Portugal. Small Business Economics, 30, 49-58. doi:10.1007/s11187-0079055-0

Baumol, W. (2010). The Microtheory of the innovative Entrepreneur. Princeton: Princeton University Press.

Boschma, R. (2005). Proximity and innovation: A critical assessment. Regional Studies, 39, 61-74. doi:10.1080/0034340052000320887

Boschma, R. (2015). Towards an evolutionary perspective on regional resilience. Regional Studies, 49(5), 733-751. doi:10.1080/ 00343404.2014.959481

Boschma, R., \& Frenken, K. (2006). Why is economic geography not an evolutionary science? Towards an evolutionary economic geography. Journal of Economic Geography, 6(3), 273-302. doi:10.1093/jeg/lbi022

Boschma, R., \& Iammarino, S. (2009). Related variety, trade linkages, and regional growth in Italy. Economic Geography, 85, 289-311. doi:10.1111/j.1944-8287.2009.01034.x

Boschma, R., \& Martin, R. L. (2007). Editorial: Constructing an evolutionary economic geography. Journal of Economic Geography, 7(5), 537-548. doi:10.1093/jeg/lbm021

Boschma, R., Minondo, A., \& Navarro, M. (2012). Related variety and regional growth in Spain. Papers in Regional Science, 91(2), 241-256. doi:10.1111/j.1435 5957.2011.00387.x.

Breschi, S., Lissoni, F., \& Malerba, F. (2003). Knowledge-relatedness in firm technological diversification. Research Policy, 32, 69-68. doi:10.1016/S0048-7333(02)00004-5

Breschi, S., Malerba, F., \& Orsenigo, L. (2000). Technological regimes and Schumpeterian patterns of innovation. Economic Journal, 110, 388-410. doi:10.1111/1468-0297.00530

Bristow, G., \& Healy, A. (2014). Regional resilience: An agency perspective. Regional Studies, 48, 923-935. doi:10.1080/00343404. 2013.854879

Bryce, D. J., \& Winter, S. G. (2009). A general interindustry relatedness index. Management Science, 55(9), 1570-1585. doi:10.1287/ mnsc. 1090.1040

Capello, R., Caragliu, A., \& Fratesi, U. (2015). Spatial heterogeneity in the costs of the economic crisis in Europe: Are cities sources of regional resilience? Journal of Economic Geography, 15(5), 951972. doi:10.1093/jeg/lbu053

Christopherson, S., Michie, J., \& Tyler, P. (2010). Regional resilience: Theoretical and empirical perspectives. Cambridge Journal 
of Regions, Economy and Society, 3, 3-10. doi:10.1093/cjres/ rsq004

Cohen, W., \& Levinthal, D. A. (1989). Innovation and learning: The two faces of R\&D. Economic Journal, 99, 569-559. doi:10.2307/ 2233763

Content, J., \& Frenken, K. (2016). Related variety and economic development: A literature review. European Planning Studies, 24(12), 2097-2112. doi:10.1080/09654313.2016.1246517

Crescenzi, R., Luca, D., \& Milio, S. (2016). The geography of the economic crisis in Europe: National macroeconomic conditions, regional structural factors and short-term economic performance. Cambridge Journal of Regions, Economy and Society, 9(1), 13-32.

Delgado, M., \& Porter, M. E. (2018). Clusters and the great recession. Retrieved from https://www.dropbox.com/s/o284y6gzloawdpk/ DPS_Clusters_GreatRecession_Paper.pdf?dl=0

Di Caro, P. (2015). Recessions, recoveries and regional resilience: Evidence on Italy. Cambridge Journal of Regions, Economy and Society, 8(2), 273-229. doi:10.1093/cjres/rsu029

Dijkstra, L., Garcilazo, E., \& McCann, P. (2015). The effects of the global financial crisis on European regions and cities. Journal of Economic Geography, 15(5), 935-949. doi:10.1093/jeg/lbv032

Diodato, D., \& Weterings, A. B. (2015). The resilience of regional labour markets to economic shocks: Exploring the role of interactions among firms and workers. Journal of Economic Geography, 15(4), 723-742. doi:10.1093/jeg/lbu030

Doran, J., McCarthy, N., \& O'Connor, M. (2016). Entrepreneurship and employment growth across European regions. Regional Studies, Regional Science, 3(1), 121-128. doi:10.1080/21681376. 2015.1135406

Essletzbichler, J. (2015). Relatedness, industrial branching and technological cohesion in US metropolitan areas. Regional Studies, 49(5), 752-766. doi:10.1080/00343404.2013.806793

Feldman, M. P., \& Audretsch, D. (1999). Innovation in cities: Science-based diversity, specialization and localized competition. European Economic Review, 43, 409-429. doi:10.1016/S00142921(98)00047-6

Fingleton, B., Garretsen, H., \& Martin, R. (2012). Recessionary shocks and regional employment: Evidence on the resilience of U.K. regions. Journal of Regional Science, 52, 109-133. doi:10. 1111/j.1467-9787.2011.00755.x

Fingleton, B., \& Palombi, S. (2013). Spatial panel data estimation, counterfactual predictions, and local economic resilience among British towns in the Victorian era. Regional Science and Urban Economics, 43, 649-660. doi:10.1016/j.regsciurbeco.2013.04. 005

Fleming, L. (2001). Recombinant uncertainty in technological search. Management Science, 47(1), 117-132. doi:10.1287/mnsc.47.1. 117.10671

Fleming, L., \& Sorenson, O. (2001). Technology as a complex adaptive system: Evidence from patent data. Research Policy, 30(7), 1019-1039. doi:10.1016/S0048-7333(00)00135-9

Frenken, K., Van Oort, F. G., \& Verburg, T. (2007). Related variety, unrelated variety and regional economic growth. Regional Studies, 41, 685-697. doi:10.1080/00343400601120296

Fritsch, M. (2013). New business formation and regional development: A survey and assessment of the evidence. Foundations and Trends in Entrepreneurship, 9, 249-364. doi:10.1561/ 0300000043

Fritsch, M., \& Mueller, A. (2004). The effects of new business formation on regional development over time. Regional Studies, 38, 961-975. doi:10.1080/0034340042000280965

Gardiner, B., Martin, R., Sunley, P., \& Tyler, P. (2013). Spatially unbalanced growth in the British economy. Journal of Economic Geography, 13(6), 889-928. doi:10.1093/jeg/lbt003

Glaeser, E. L., Kallal, H. D., Scheinkman, J. A., \& Shleifer, A. (1992). Growth in cities. Journal of Political Economy, 100, 1126-1152. doi:10.1086/261856
Glaeser, E. L., \& Kerr, W. R. (2009). Local industrial conditions and entrepreneurship: How much of the spatial distribution can we explain? Journal of Economics and Management Strategy, 18, 623-663. doi:10.1111/j.1530-9134.2009.00225.x

Grabher, G., \& Stark, D. (1997). Organizing diversity: Evolutionary theory, network analysis and postsocialism. Regional Studies, 31, 533-544. doi:10.1080/00343409750132315

Griliches, Z., Pakes, Z., \& Hall, B. H. (1987). The value of patents as indicators of inventive activity. In P. Dasgupta, \& P. Stoneman (Eds.), Economic policy and technological performance. Cambridge: Cambridge University Press.

Haltiwanger, J., Jarmin, R. S., \& Miranda, J. (2013). Who creates jobs? Small vs. large vs. young. Review of Economics and Statistics, 95(2), 347-361. doi:10.1162/REST_a_00288

Hidalgo, C., Klinger, B., Barabasi, A., \& Hausmann, R. (2007). The product space conditions the development of nations. Science, 317, 482-487. doi:10.1126/science. 1144581

Holm, J., \& Østergaard, C. R. (2015). Regional employment growth, shocks and regional industrial resilience: A quantitative analysis of the Danish ICT sector. Regional Studies, 49, 95-112. doi:10. 1080/00343404.2013.787159

Jacobs, J. (1969). The economy of cities. New York: Vintage.

Jacquemin, A. P., \& Berry, C. (1979). Entropy measure of diversification and corporate growth. Journal of Industrial Economics, 27 (4), 359-369. doi:10.2307/2097958

Jaffe, A. (1986). Technological opportunity and spillovers of R\&D. American Economic Review, 76, 984-1001.

Jaffe, A. B., \& Trajtenberg, M. (2002). Patents, citations, and innovations: A window on the knowledge economy. Boston: MIT Press.

Kitsos, A., \& Bishop, P. (2016). Economic resilience in Great Britain: The crisis impact and its determining factors for local authority districts. Annals of Regional Science, 1-19. doi:10. 1007/s00168-016-0797-y

Kogler, D. F., Essletzbichler, J., \& Rigby, D. L. (2017). The evolution of specialization in the EU15 knowledge space. Journal of Economic Geography, 17(2), 345-373. doi:10.1093/jeg/lbw024

Lee, N. (2014). Grim down South? The determinants of unemployment increases in British cities in the 2008-2009 recession. Regional Studies, 48, 1761-1778. doi:10.1080/00343404.2012. 709609

Malerba, F. (Ed.). (2004). Sectoral systems of innovation: Concepts, issues and analyses of six major sectors in Europe. Cambridge: Cambridge University Press.

Martin, R. (2012). Regional economic resilience, hysteresis and recessionary shocks. Journal of Economic Geography, 12, 1-32. doi:10. 1093/jeg/lbr019

Nagaoka, S., Motohashi, K., \& Goto, A. (2010). Patent statistics as an innovation indicator. In B. H. Hall, \& N. Rosenberg (Eds.), Handbook of the economics of innovation (Vol. 1, pp. 10841127). Amsterdam: Elsevier.

Neffke, F., Henning, M., \& Boschma, R. (2011). How do regions diversify over time? Industry relatedness and the development of new growth paths in regions. Economic Geography, 87, 237265. doi:10.1111/j.1944-8287.2011.01121.x

Nesta, L., \& Saviotti, P. P. (2005). Coherence of the knowledge base and the firm's innovative performance: Evidence from the U.S. pharmaceutical industry. Journal of Industrial Economics, 53, 123-142. doi:10.1111/j.0022-1821.2005.00248.x

Nesta, L., \& Saviotti, P. P. (2006). Firm knowledge and market value in biotechnology. Industrial and Corporate Change, 15(4), 625652. doi:10.1093/icc/dt1007

Nightingale, P., \& Coad, A. (2014). Muppets and gazelles: Political and methodological biases in entrepreneurship research. Industrial and Corporate Change, 23(1), 113-143. doi:10.1093/ icc/dtt057

Nooteboom, B. (2000). Learning and innovation in organizations and economies. Oxford: Oxford University Press. 
Nooteboom, B., Van Haverbeke, W., Duysters, G., Gilsing, V., \& Van den Oord, A. (2007). Optimal cognitive distance and absorptive capacity. Research Policy, 36(7), 1016-1034. doi:10. 1016/j.respol.2007.04.003

Organisation for Economic Co-operation and Development (OECD). (2014). OECD regional outlook 2014 regions and cities: Where policies and people meet. Paris: OECD Publ.

Pasinetti, L. (1993). Structural economics dynamics. Cambridge: Cambridge University Press.

Picard, P. M., \& van Pottelsberghe de la Potterie, B. (2011). Patent office governance and patent system quality (CEPR Discussion Paper No. DP8338). Retrieved from SSRN https://ssrn.com/ abstract $=1815813$

Pike, A., Dawley, S., \& Tomaney, J. (2010). Resilience, adaptation and adaptability. Cambridge Journal of Regions, Economy and Society, 3(1), 59-70. doi:10.1093/cjres/rsq001

Plum, O., \& Hassink, R. (2014). Knowledge bases, innovativeness and competitiveness in creative industries: The case of Hamburg's video game developers. Regional Studies, Regional Science, 1(1), 248-268. doi:10.1080/21681376.2014.967803

Porter, M. E. (2003). The economic performance of regions. Regional Studies, 37, 549-578. doi:10.1080/0034340032000108688

Quatraro, F. (2010). Knowledge Coherence, variety and economic growth: Manufacturing evidence from Italian regions. Research Policy, 39, 1289-1302.

Reggiani, A., de Graff, T., \& Nijkamp, P. (2002). Resilience: An evolutionary approach to spatial economic systems. Networks and Spatial Economics, 2, 211-229. doi:10.1023/A:1015377515690

Saviotti, P. P. (1996). Technological evolution, variety and the economy. Cheltenham: Edward Elgar.

Saxenian, A. (1994). Regional advantage: Culture and competition in Silicon Valley and Route 128. Cambridge, MA: Harvard University.

Schumpeter, J. (1934). The theory of economic development. Cambridge, MA: Harvard University Press.

Sedita, S. R., De Noni, I., \& Pilotti, L. (2014). How do related variety and differentiated knowledge bases influence the resilience of local production systems? (No. 0180). Dipartimento di Scienze Economiche 'Marco Fanno'.
Sensier, M., Bristow, G. I., \& Healy, A. (2016). Measuring regional economic resilience across Europe: Operationalising a complex concept. Spatial Economic Analysis, 11(2), 128-151.

Shane, S. (2009). Why encouraging more people to become entrepreneurs is bad public policy. Small Business Economics, 33, 141-149. doi:10.1007/s11187-009-9215-5

Simmie, J., \& Martin, R. (2010). The economic resilience of regions: Towards an evolutionary approach. Cambridge Journal of Regions, Economy and Society, 3(1), 27-43. doi:10.1093/cjres/rsp029

Suire, R., \& Vicente, J. (2009). Why do some places succeed when others decline? A social interaction model of cluster viability. Journal of Economic Geography, 9(3), 381-404. doi:10.1093/jeg/ lbn053

Teece, D. J., Rumelt, R., Dosi, G., \& Winter, S. (1994). Understanding corporate coherence: Theory and evidence. Journal of Economic Behavior and Organisation, 23, 1-30. doi:10.1016/0167-2681(94)90094-9

Theil, H. (1967). Economics and information theory. Amsterdam: North-Holland.

Theil, H. (1972). Statistical decomposition analysis. Amsterdam: North-Holland.

Treado, C. D. (2009). Pittsburgh's evolving steel legacy and the steel technological cluster. Cambridge Journal of Regions, Economy and Society, 3(1), 105-120.

Van Praag, C. M., \& Versloot, P. H. (2007). What is the value of entrepreneurship? A review of recent research. Small Business Economics, 29(4), 351-382. doi:10.1007/s11187007-9074-x

Walker, B., Gunderson, L., Kinzig, A., Folke, C., Carpenter, S., \& Schultz, L. (2006). A handful of heuristics and some propositions for understanding resilience in socio-ecological systems. Ecology and Society, 11(1), 13.

Weitzman, M. L. (1998). Recombinant growth. Quarterly Journal of Economics, 113, 331-360. doi:10.1162/003355398555595

Wolfe, D. A. (2010). The strategic management of core cities: Path dependence and economic adjustment in resilient regions. Cambridge Journal of Regions, Economy and Society, 3, 139-152. 